\title{
Association between pre-pregnancy weight status and maternal micronutrient status in early pregnancy
}

\author{
Judith M Scholing ${ }^{1,2}$, Margreet R Olthof ${ }^{2}$, Femkje AM Jonker ${ }^{3}$ and Tanja GM Vrijkotte ${ }^{1, *}$ \\ 'Department of Public Health, Amsterdam Public Health Research Institute, Academic Medical Center, University of \\ Amsterdam, Postbox 22660, 1100 DD Amsterdam, The Netherlands: ${ }^{2}$ Department of Health Sciences, Faculty of \\ Earth \& Life Sciences, Vrije Universiteit Amsterdam, Amsterdam Public Health Research Institute, Amsterdam, \\ The Netherlands: ${ }^{3}$ Global Child Health Group, Amsterdam Institute of Global Health and Development, Amsterdam, \\ The Netherlands
}

Submitted 25 July 2017: Final revision received 27 January 2018: Accepted 5 February 2018: First published online 21 March 2018

\begin{abstract}
Objective: Inadequate maternal micronutrient status during pregnancy can lead to short- and long-term health risks for mother and offspring. The present study investigated the association between pre-pregnancy weight status and micronutrient status during pregnancy.

Design: Maternal blood samples were collected during early pregnancy (median 13, interquartile range 12-15 weeks) and were assayed for serum folate, ferritin, Fe and vitamin $B_{12}$. Regression modelling was used to assess the association between pre-pregnancy underweight, normal weight, overweight and obesity, and micronutrient levels, as well as the odds for deficiencies.

Setting: The Amsterdam Born Children and their Development (ABCD) study, the Netherlands.

Subjects: Women with singleton pregnancies without diabetes ( $n$ 4243).

Results: After adjustment for covariates, overweight women and obese women had lower $(\beta ; 95 \% \mathrm{CI})$ folate $(-1 \cdot 2 ;-2 \cdot 2,-0 \cdot 2$ and $-2 \cdot 3 ;-4 \cdot 0,-0 \cdot 7 \mathrm{nmol} / 1$, respectively) and $\mathrm{Fe}(-1 \cdot 7 ;-2 \cdot 3,-1 \cdot 1$ and $-3 \cdot 6 ;-4 \cdot 7,-2 \cdot 6 \mu \mathrm{mol} / 1$, respectively) levels than women with normal weight. Furthermore, overweight women had 6\% (95\% CI $-9,-3 \%)$ and obese women had $15 \%(-19,-10 \%)$, lower vitamin $\mathrm{B}_{12}$ levels, and obese women had 19\% (6, 32\%) higher ferritin levels, than normal-weight women. Obese women had higher odds (OR; 95\% CI) for folate deficiency (2.03; $1 \cdot 35,3 \cdot 06)$, Fe deficiency $(3 \cdot 26 ; 2 \cdot 09,5 \cdot 08)$ and vitamin $B_{12}$ deficiency $(2 \cdot 05 ; 1 \cdot 41$, 2.99) than women with normal weight. Underweight was not associated with micronutrient status.

Conclusions: During early pregnancy, women with pre-pregnancy overweight and obesity had lower serum folate, Fe and vitamin $\mathrm{B}_{12}$ status. This resulted in increased risk of serum folate, $\mathrm{Fe}$ and vitamin $\mathrm{B}_{12}$ deficiencies in women with obesity.
\end{abstract}

In Europe, approximately 3-9\% of women who enter pregnancy are underweight and $30-37 \%$ are overweight or obese ${ }^{(1)}$. Being underweight or overweight during pregnancy is associated with several health risks for both mother and child. Maternal overweight and obesity is associated with a higher risk of multiple adverse pregnancy conditions such as pre-eclampsia, gestational diabetes, preterm delivery, neural tube defects and congenital anomalies $^{(2-4)}$. Being underweight during pregnancy is associated with a higher risk of preterm delivery, small for gestational age and a low birth weight ${ }^{(5)}$.

A low micronutrient status during pregnancy can lead to similar adverse pregnancy outcomes and might explain part of the relationship between weight status and adverse pregnancy outcomes ${ }^{(6)}$. Studies in Western countries have indicated a J-shaped association between maternal weight status and micronutrient status in non-pregnant women of childbearing age: underweight as well as overweight and obese women have lower levels of several micronutrients compared with women with normal weight ${ }^{(7-11)}$. In developed countries, whereas a lower micronutrient status in underweight women might be due to inadequate food intake and unhealthy eating habits ${ }^{(12)}$, in overweight and obese individuals the cause is probably multifactorial, for example both poor diet quality and biological factors related to obesity (such as chronic low-grade inflammation) ${ }^{(13,14)}$. 
Folate, Fe and vitamin $\mathrm{B}_{12}$ are important micronutrients during pregnancy; moreover, because the requirements for these nutrients increase considerably during pregnancy, pregnant women have a higher risk of deficiencies than non-pregnant individuals ${ }^{(6,15)}$. Deficiency of each of these nutrients is associated with several short- and long-term health risks for both mother and child ${ }^{(16)}$. A low maternal folate status is known to increase the risk of neural tube defects, especially in combination with a low vitamin $\mathrm{B}_{12}$ status $^{(16)}$. In the long term, maternal folate and vitamin $B_{12}$ deficiency during pregnancy is associated with a higher heart rate in the offspring at age 5 years and an increased risk of insulin resistance at age 6 years ${ }^{(17,18)}$. A low maternal Fe status during pregnancy is associated with an increased risk of small-for-gestational-age infants and preterm delivery $^{(19-21)}$. In the long term, maternal Fe deficiency is associated with delayed neurocognitive development during childhood, which can persist into adulthood ${ }^{(22)}$.

While several studies have found an association between weight status and folate, Fe and vitamin $\mathrm{B}_{12}$ in non-pregnant women, few studies have focused on this association during pregnancy. A study in a white British pregnant population found that a higher pre-pregnancy BMI (pBMI) was associated with lower folate levels at 28 weeks of gestation ${ }^{(23)}$. However, a study from the USA found lower folate levels at 20 weeks of gestation for overweight women but not for obese women ${ }^{(24)}$. Furthermore, two studies from Spain and the USA found that a higher pBMI is associated with a lower status of $\mathrm{Fe}$ at 24, 26 and 34 weeks of gestation ${ }^{(25,26)}$. Additionally, a study in a Chinese pregnant population found that a higher pBMI is associated with a lower status of the Fe storage protein ferritin at 20 weeks of gestation; however, this association has not been confirmed in Western pregnant populations ${ }^{(25-27)}$.

To date, most studies have focused on micronutrient status in the last trimester of pregnancy, while the first trimester of pregnancy is the most critical period for the development of deficiency-related health risks during pregnancy $^{(6)}$. In addition, no studies have investigated the nutritional status of pregnant women who are underweight. Therefore, uncertainty still exists about the association between weight status and micronutrient status during early pregnancy.

The present study investigated the association between pre-pregnancy weight status and folate, Fe, ferritin and vitamin $\mathrm{B}_{12}$ status, and the risk for deficiencies in these nutrients, in a large cohort of women during early pregnancy.

\section{Methods}

\section{Study design}

The Amsterdam Born Children and their Development (ABCD) study is a prospective observational cohort study that aims to investigate the associations between maternal lifestyle, medical, dietary and environmental conditions during pregnancy and their children's health at birth and later in life ${ }^{(28)}$. In 2003 and 2004, all pregnant women in Amsterdam were invited to participate in the ABCD study during their first appointment at their obstetric caregiver ${ }^{(28)}$. Within two weeks, a written informed consent sheet and a pregnancy questionnaire about sociodemographic characteristics, obstetric history, lifestyle, medical conditions and psychosocial conditions were sent to the women. In addition, the women were invited to participate in the ABCD biomarker study. Three months after birth, all mothers who filled in the pregnancy questionnaire were followed-up with an infant questionnaire to obtain information on the course of the pregnancy and delivery, in addition to the health and development of the baby ${ }^{(28)}$.

\section{Study sample}

In the present study, women were included when data were available on their weight status and at least one valid nutrient measurement. Excluded were twin pregnancies and women with pre-existent and gestational diabetes, since these conditions can influence the nutrient status of women $^{(29,30)}$. The final study sample consisted of 4243 pregnant women (Fig. 1).

\section{Measurements}

Weight status was determined by pBMI. The variable pBMI was computed using self-reported pre-pregnancy weight and height of the participants, obtained from the pregnancy questionnaire. The variable was considered continuous for explorative analyses and divided into four categories for additional analyses: underweight $\left(\right.$ BMI $\left.<18.5 \mathrm{~kg} / \mathrm{m}^{2}\right)$, normal weight $\left(\right.$ BMI $\left.=18.5-24.9 \mathrm{~kg} / \mathrm{m}^{2}\right)$, overweight $\left(\mathrm{BMI}=25 \cdot 0-29 \cdot 9 \mathrm{~kg} / \mathrm{m}^{2}\right)$ and obesity $\left(\mathrm{BMI} \geq 30 \cdot 0 \mathrm{~kg} / \mathrm{m}^{2}\right)^{(31)}$.

Non-fasting blood samples were taken during early pregnancy (median 13 weeks, interquartile range (IQR) 12-15 weeks), during the routine blood collection for screening purposes at the first antenatal check-up. The blood samples were collected in a $10 \mathrm{ml}$ EDTA (K2) Vacutainer $^{(B}$ (Becton and Dickson BV, Alphen aan de Rijn, the Netherlands) for the preparation of plasma and in a $9 \mathrm{ml}$ evacuated tube (Vacuette ${ }^{\circledR}$; Breiner BV, Alphen aan de Rijn, the Netherlands) for the preparation of serum. After blood collection, the blood samples were sent to the Regional Laboratory of Amsterdam, by courier or by overnight mail, for further processing. This process did not influence the validity of specific biomarkers ${ }^{(32)}$. At the laboratory, plasma and serum were prepared by centrifugation and then stored as $1 \mathrm{ml}$ aliquots at $-80^{\circ} \mathrm{C}$ until analysis at the laboratory.

The analysis of vitamin $\mathrm{B}_{12}$ and Fe status in serum was performed by the laboratory of the National Institute for Public Health and the Environment (RIVM, Bilthoven, the Netherlands). The analyses of both vitamin $\mathrm{B}_{12}$ and $\mathrm{Fe}$ were performed in the second half of 2005, a median of $24 \cdot 5$ (IQR 21·1-28.4) months after storage. For vitamin $B_{12}$ 


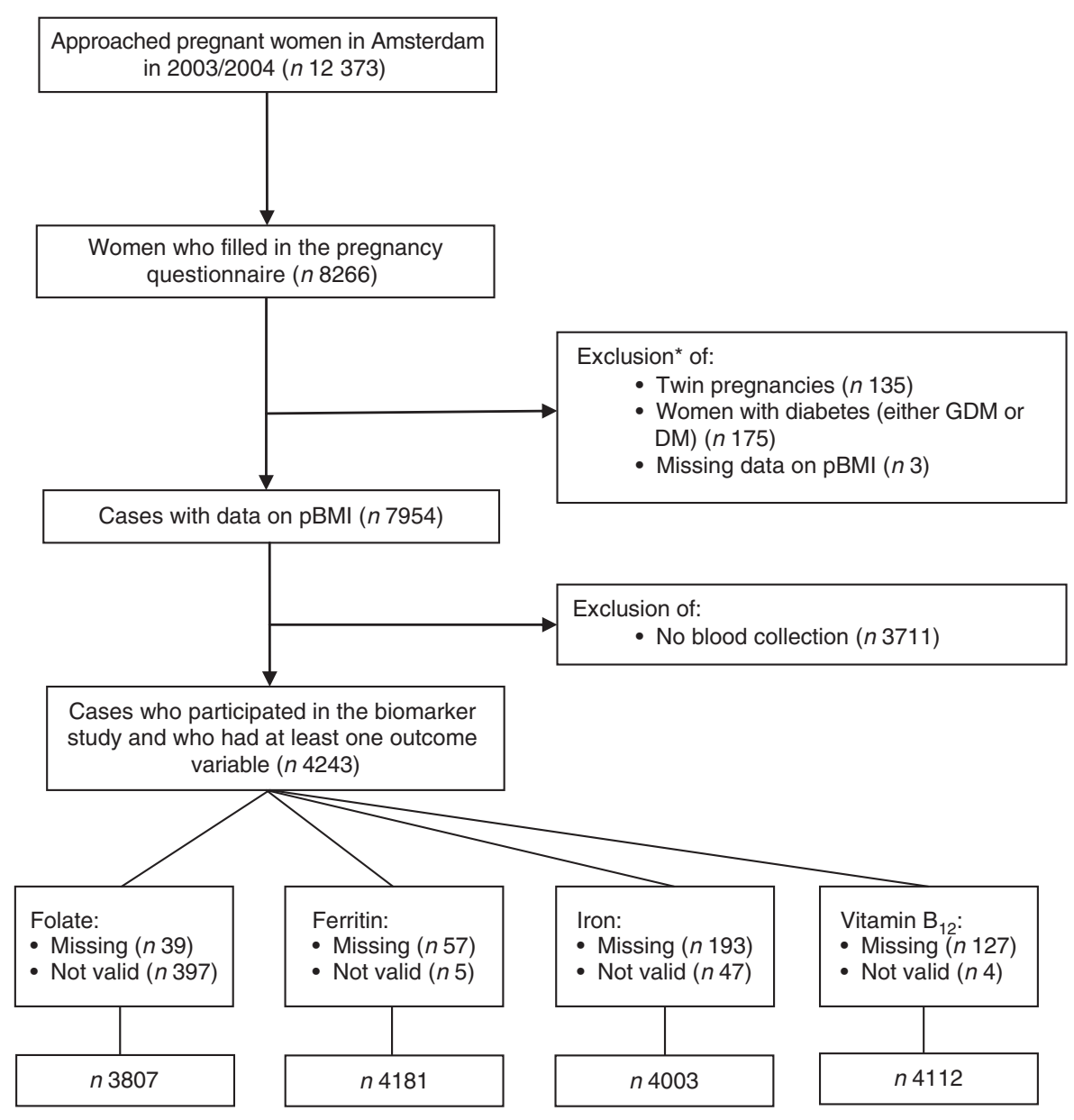

Fig. 1 Flowchart of the study sample. *The sum of the excluded cases is greater than the total excluded cases because of overlap in the excluded variables (pBMI, pre-pregnancy BMI; DM, diabetes mellitus; GDM, gestational diabetes mellitus)

status, an immunoassay with chemiluminescence detection on the Access Immunoassay System (Beckman Coulter, Woerden, the Netherlands) was used ${ }^{(33)}$. The interassay $\mathrm{CV}$ for vitamin $\mathrm{B}_{12}$ was $7 \cdot 8 \%$ for low values and $7 \cdot 6 \%$ for high values. The upper detection limit was $1500 \mathrm{pg} / \mathrm{ml}$. The reliability of the measurements analysed at RIVM was determined by the HIL index: when a serum specimen contains $\mathrm{Hb}$ (haemolysis, $\mathrm{H}$ ), bilirubin (icterus, I) or lipids (lipoedema, L), the test could be negatively affected. The vitamin $\mathrm{B}_{12}$ data were considered unreliable at values of $\mathrm{H}>1400, \mathrm{I}>30$ and/or $\mathrm{L}>250$. For assessment of serum Fe, in vitro colorimetric assay on the Hitachi 912 Analyser (Roche Diagnostics, Mannheim, Germany) was used. The inter-assay $\mathrm{CV}$ for serum Fe was $1.5 \%$. Data of serum Fe were considered unreliable at values of $\mathrm{H}>80, \mathrm{I}>60$ and/or $\mathrm{L}>100$.

The analyses of folate and ferritin status in serum were performed in the Medical Laboratory Dr. Stein \& Collegae (Maastricht, the Netherlands) ${ }^{(33)}$. These analyses were performed at a median of $3 \cdot 6$ (IQR 3.1-4.1) months after storage of the sample. Both nutrients were determined by performing an immunoassay with chemiluminescence detection on the Advia Centaur System (Bayer Group, Mijdrecht, the Netherlands). For folate, the inter-assay CV was $6 \cdot 1 \%$ for low values and $5.3 \%$ for high values; the upper and lower detection limits were 54.4 and $0.8 \mathrm{nmol} / \mathrm{l}$, respectively ${ }^{(17,33)}$. For ferritin, the inter-assay CV was $7 \cdot 9 \%$ for low values and $2.7 \%$ for high values. All samples were within detection limit. All nutrients with measurements that were above the HIL-index criteria and/or were above/ below the detection limits were excluded (Fig. 1).

\section{Covariates}

Information on the use of supplemental $\mathrm{Fe}$, vitamin $\mathrm{B}_{12}$ and folate (yes, no) was extracted from self-reported information in the infant questionnaire. Information on potential confounding variables was obtained from the pregnancy questionnaire; these included maternal age (years), education after primary school (years), smoking behaviour in early pregnancy (no smoking, $<1,1-5$ or $>5$ cigarettes/d), alcohol intake in early pregnancy (yes, no), parity (nulliparous, multiparous), nausea during pregnancy (yes, no), weight gain during early pregnancy ( $<0.3 \mathrm{~kg} /$ month, $0.3-1.0 \mathrm{~kg} /$ month or $>1.0 \mathrm{~kg} / \mathrm{month})$ and ethnicity, based on country of birth of the pregnant woman (Dutch, African, Moroccan, Turkish, other Western or other non-Western). 
C-reactive protein levels were determined in serum at the Medical Laboratory Dr. Stein \& Collegae. Samples were analysed at a median of $3 \cdot 6$ (IQR 3.1-4.1) months after storage of the sample. C-reactive protein was determined by highsensitivity assay (Dade-Behring, Leusden, the Netherlands). The inter-assay CV was 5.2\% for low values and $2.6 \%$ for high values; the lower detection limit was $0.5 \mathrm{mg} / \mathrm{l}$.

\section{Statistical analyses}

First, the demographics of the study population were determined for the whole sample, as well as for each separate pBMI category. Differences between the pBMI groups were tested for significance by performing a oneway ANOVA or a $\chi^{2}$ test. After one-way ANOVA, a post hoc test was performed (reference category: normal weight): the Bonferroni post hoc test when the variances were equally distributed and the Games-Howell post hoc test when the variances were unequally distributed. In addition, a non-response analysis was conducted to compare the response group (non-diabetic, singleton pregnancies) with the non-response group (non-diabetic, singleton pregnancies and no participation the ABCD biomarker study) on demographic characteristics. The demographic characteristics in these two groups were tested by the independent $t$ test or the $\chi^{2}$ test.

Next, all data on nutrient status were standardized for the gestational age at blood sampling moment, because the week of pregnancy could influence nutrient status ${ }^{(34)}$. All serum micronutrient levels were calculated back to the median of 13 weeks. Ferritin and vitamin $\mathrm{B}_{12}$ levels were natural log transformed for all further analyses to correct for their skewed distribution. For the interpretation of the log-transformed data, results were back-transformed by taking the exponential of the log-transformed regression coefficients.

To explore the association between pBMI (continuous) and nutrient status, charts for each nutrient were generated by using restricted cubic spline modelling. These charts were generated both with and without adjustment for maternal age, education, parity, smoking during pregnancy, alcohol use during pregnancy, nausea during pregnancy, weight gain during pregnancy and ethnicity. An ANOVA was performed to check for linearity. If nonlinearity was observed, a likelihood ratio test was performed to test whether this non-linear model better fitted the association than the linear model.

Next, descriptive analyses were performed on the nutrient status (mean and SD/median and IQR) and, for each nutrient, we calculated the percentage of women who were deficient. A nutrient status below the following values was considered deficient: serum folate $<10 \cdot 0 \mathrm{nmol} / 1$ and ferritin $<15 \cdot 0 \mu \mathrm{g} / \mathrm{l}$, according to the WHO cut-off values for folate and ferritin ${ }^{(35,36)}$. WHO cut-off values for Fe and vitamin $\mathrm{B}_{12}$ were not available and therefore reference values for nonpregnant women from the medical laboratory in the Academic Medical Center (Amsterdam, the Netherlands) were used $^{(37)}: \mathrm{Fe}<11.0 \mu \mathrm{mol} / \mathrm{l}$ and vitamin $\mathrm{B}_{12}<203.3 \mathrm{pg} / \mathrm{ml}$.
Linear regression modelling was used to assess the association between pBMI (categorical, reference category: normal weight) and each nutrient level (model 1). The model was then adjusted for maternal age, education, smoking during pregnancy, alcohol use during pregnancy, parity, nausea during pregnancy, weight gain during pregnancy and ethnicity (model 2).

Logistic regression modelling was performed to assess the association between pBMI (categorical, reference category: normal weight) and nutrient deficiency per nutrient (yes, no). This model was also adjusted for all covariates in model 2.

Two sensitivity analyses were performed. The first investigated the abovementioned associations in a more homogeneous sample including women of Dutch ethnicity only; the second included only those women who did not use supplements during pregnancy.

Statistical analyses were performed using the statistical software packages IBM SPSS Statistics version 22, $\mathrm{R}$ version 3.2.3 and R-studio version 0.99.891. $P<0.05$ was considered statistically significant.

\section{Results}

\section{Population characteristics}

Table 1 presents the characteristics of the study population. Women who were underweight were significantly younger, had fewer years of education, were less likely to be Dutch, and had less weight gain during pregnancy compared with women with a normal weight. Overweight women were younger than normal-weight women, and both overweight and obese women had fewer years of education, were less likely to be Dutch, and drank less alcohol during pregnancy compared with women with a normal weight. Overweight and obese women were more likely to have hypertension, had more weight gain and more nausea during pregnancy, and were less likely to use folate supplements. In addition, overweight and obese women had higher C-reactive protein levels compared with normal-weight women.

The non-response analysis showed that, compared with those who did not participate in the biomarker study, the included women were significantly more likely to be Dutch and nulliparous, have more years of education, a lower pBMI, and more often use alcohol during pregnancy (see online supplementary material, Table S1).

\section{Maternal micronutrient status}

Restricted cubic spline modelling showed a non-linear association for pBMI (continuous) and serum folate in the non-adjusted model (Fig. 2(a)). However, after correcting for covariates, the non-linear model did not show a significantly better fit than the linear model (Fig. 2(e)). Restricted cubic spline modelling also showed a nonlinear association between pBMI and serum Fe in both 
Table 1 Characteristics of the study population according to category of pre-pregnancy BMI (pBMI): women with singleton pregnancies without diabetes ( $n$ 4243), the Amsterdam Born Children and their Development (ABCD) study, the Netherlands, 2003-2004

\begin{tabular}{|c|c|c|c|c|c|c|c|c|c|c|}
\hline \multirow[b]{2}{*}{ Maternal characteristic } & \multicolumn{2}{|c|}{$\begin{array}{c}\text { Total } \\
(n \text { 4243) }\end{array}$} & \multicolumn{2}{|c|}{$\begin{array}{l}\text { Underweight } \\
(\text { (n 196) }\end{array}$} & \multicolumn{2}{|c|}{$\begin{array}{l}\text { Normal weight } \\
\quad(n \text { 3154) }\end{array}$} & \multicolumn{2}{|c|}{$\begin{array}{l}\text { Overweight } \\
\text { (n 682) }\end{array}$} & \multicolumn{2}{|c|}{$\begin{array}{l}\text { Obese } \\
(n 211)\end{array}$} \\
\hline & $\begin{array}{c}\text { Mean or } \\
n\end{array}$ & SD or \% & $\begin{array}{c}\text { Mean or } \\
n\end{array}$ & SD or $\%$ & $\begin{array}{c}\text { Mean or } \\
n\end{array}$ & SD or \% & $\begin{array}{c}\text { Mean or } \\
n\end{array}$ & SD or \% & $\begin{array}{c}\text { Mean or } \\
n\end{array}$ & SD or $\%$ \\
\hline pBMI (kg/m²) & $22 \cdot 9$ & $3 \cdot 8$ & $17 \cdot 7$ & 0.76 & $21 \cdot 6$ & 1.7 & $27 \cdot 0$ & 1.4 & $33 \cdot 8$ & 4.0 \\
\hline Age (years) & $30 \cdot 9$ & 4.9 & $29 \cdot 4^{\star \star \star}$ & $5 \cdot 1$ & $31 \cdot 1$ & 4.7 & $30 \cdot 6^{\star}$ & $5 \cdot 1$ & 31.0 & 5.5 \\
\hline Parity, nulliparous & 2465 & $58 \cdot 1$ & 114 & $58 \cdot 2$ & 1935 & 61.4 & 336 & $49 \cdot 3^{\star \star *}$ & 80 & $37 \cdot 9^{\star \star \star}$ \\
\hline \multicolumn{11}{|l|}{ Ethnicity } \\
\hline Dutch & 2521 & 59.5 & 91 & $46 \cdot 4^{\star \star \star}$ & 2012 & $63 \cdot 8$ & 337 & $49 \cdot 6^{\star \star \star}$ & 81 & $38 \cdot 9^{\star \star \star}$ \\
\hline African & 262 & $6 \cdot 2$ & 11 & $5 \cdot 6$ & 127 & 4.0 & 81 & $12 \cdot 0$ & 43 & $20 \cdot 7$ \\
\hline Moroccan & 260 & $6 \cdot 1$ & 9 & 4.6 & 134 & 4.3 & 88 & $12 \cdot 9$ & 29 & $13 \cdot 9$ \\
\hline Turkish & 177 & $4 \cdot 2$ & 13 & $6 \cdot 6$ & 110 & 3.5 & 40 & 5.9 & 14 & $6 \cdot 7$ \\
\hline Other Western & 604 & $14 \cdot 3$ & 33 & $16 \cdot 8$ & 490 & $15 \cdot 5$ & 65 & $9 \cdot 6$ & 16 & 7.7 \\
\hline Other non-Western & 412 & $9 \cdot 7$ & 39 & $19 \cdot 9$ & 279 & 8.9 & 69 & $10 \cdot 1$ & 25 & $12 \cdot 0$ \\
\hline Education after primary school (years) & $9 \cdot 3$ & $3 \cdot 8$ & $8 \cdot 4^{\star \star \star}$ & $4 \cdot 1$ & $9 \cdot 7$ & 3.6 & $8 \cdot 3^{\star \star \star}$ & 3.9 & $6 \cdot 6^{\star \star \star}$ & 4.0 \\
\hline \multicolumn{11}{|l|}{ Smoking during pregnancy } \\
\hline No & 3831 & $90 \cdot 4$ & 168 & $85 \cdot 7$ & 2845 & $90 \cdot 3$ & 630 & $92 \cdot 4$ & 188 & 89.5 \\
\hline$<1$ cigarette/d & 109 & $2 \cdot 6$ & 7 & 3.6 & 84 & $2 \cdot 7$ & 15 & $2 \cdot 2$ & 3 & 1.4 \\
\hline $1-5$ cigarettes $/ d$ & 166 & 3.9 & 10 & $5 \cdot 1$ & 131 & 4.2 & 17 & 2.5 & 8 & $3 \cdot 8$ \\
\hline$>5$ cigarettes $/ \mathrm{d}$ & 133 & $3 \cdot 1$ & 11 & $5 \cdot 6$ & 91 & 2.9 & 20 & 2.9 & 11 & $5 \cdot 2$ \\
\hline Alcohol use during pregnancy & 1054 & $24 \cdot 8$ & 43 & $21 \cdot 9$ & 874 & $27 \cdot 7$ & 114 & $16 \cdot 7^{\star \star \star}$ & 23 & $10 \cdot 9^{\star \star \star}$ \\
\hline \multicolumn{11}{|l|}{ Weight gain in early pregnancy } \\
\hline$<0.3 \mathrm{~kg} /$ month & 751 & $22 \cdot 1$ & 16 & $10 \cdot 4^{*}$ & 507 & $19 \cdot 8$ & 158 & $30 \cdot 6^{\star \star \star}$ & 70 & $44 \cdot 9^{\star \star \star}$ \\
\hline $0.3-1.0 \mathrm{~kg} /$ month & 1414 & $41 \cdot 7$ & 17 & $46 \cdot 1$ & 1105 & $43 \cdot 1$ & 191 & $37 \cdot 0$ & 47 & $30 \cdot 1$ \\
\hline$>1.0 \mathrm{~kg} / \mathrm{month}$ & 1227 & $36 \cdot 2$ & 67 & 43.5 & 954 & $37 \cdot 2$ & 167 & 32.4 & 39 & $25 \cdot 0$ \\
\hline Nausea during pregnancy & 1944 & $46 \cdot 3$ & 99 & $51 \cdot 3$ & 1400 & $44 \cdot 7$ & 335 & $50 \cdot 0^{*}$ & 110 & $53 \cdot 1^{\star}$ \\
\hline Hypertension during pregnancy & 468 & $11 \cdot 0$ & 12 & $6 \cdot 1$ & 292 & $9 \cdot 3$ & 112 & $16 \cdot 4^{\star \star \star}$ & 52 & $24 \cdot 6^{\star \star \star}$ \\
\hline Folate supplement use in $\mathrm{T} 1$ & 2294 & $80 \cdot 3$ & 88 & $79 \cdot 3$ & 1795 & $81 \cdot 8$ & 324 & $76 \cdot 8^{\star}$ & 87 & $66 \cdot 9^{\star \star \star}$ \\
\hline Fe supplement use in T1 & 888 & 35.9 & 32 & 34.4 & 697 & $36 \cdot 6$ & 131 & $36 \cdot 2$ & 28 & $24 \cdot 8$ \\
\hline Vitamin $B_{12}$ supplement use in $T 1$ & 845 & $32 \cdot 2$ & 30 & $29 \cdot 1$ & 664 & $33 \cdot 1$ & 123 & $31 \cdot 2$ & 28 & $23 \cdot 3$ \\
\hline Gestational age at blood sampling (weeks) & 13.5 & 3.3 & 13.5 & 3.2 & 13.4 & $3 \cdot 3$ & $13 \cdot 6$ & $3 \cdot 6$ & 13.9 & 3.5 \\
\hline C-reactive protein $(\mathrm{mg} / \mathrm{l}) \dagger$ & 3.2 & $1 \cdot 4-6 \cdot 3$ & $2 \cdot 0$ & $0.6-4.4$ & $2 \cdot 8$ & $1 \cdot 2-5 \cdot 2$ & $5 \cdot 8^{\star \star \star}$ & $2 \cdot 8-9 \cdot 2$ & $8 \cdot 2^{\star \star \star}$ & $5 \cdot 0-14 \cdot 4$ \\
\hline
\end{tabular}

T1, first trimester of pregnancy.

Data presented are mean and SD for continuous variables or $n$ and $\%$ for dichotomous and categorical variables. $P$ values for differences between pBMI groups were determined by performing a one-way ANOVA for continuous variables or a $\chi^{2}$ test for dichotomous and categorical variables; after one-way ANOVA, a post hoc test was performed using normal weight as the reference category: the Bonferroni post hoc test when the variances were equally distributed or the Games-Howell post hoc test when the variances were unequally distributed.

${ }^{\star} P<0.05,{ }^{\star \star \star} P<0.001$.

†Median and interquartile range are given because of skewed distribution of the variable.

the non-adjusted and the adjusted model (Fig. 2(c) and $2(\mathrm{~g})$ ). These non-linear models showed a significantly better fit than a linear model. Associations between pBMI and ferritin and vitamin $\mathrm{B}_{12}$ were linear, also after correcting for covariates (Fig. 2(b), 2(d), 2(f) and 2(h)).

Table 2 presents an overview of the micronutrient concentrations and prevalences of deficiency according to the pBMI categories. Of all women, $8.8 \%$ were folate deficient and $13.8 \%$ were vitamin $\mathrm{B}_{12}$ deficient. For Fe status, $10.6 \%$ of all women were ferritin deficient and $6.1 \%$ were serum Fe deficient. Micronutrient deficiencies were more prevalent in overweight and obese women than in normal-weight women, with the highest prevalence in obese women.

\section{Associations between weight status and maternal micronutrient status}

Table 3 presents the results from the linear and logistic regression modelling analyses. After correction for covariates, women with overweight had significantly lower levels of folate $(\beta=-1 \cdot 2 ; 95 \% \mathrm{CI}-2 \cdot 2,-0 \cdot 2 \mathrm{nmol} / \mathrm{l})$ compared with women with normal weight. In addition, obese women had significantly lower levels of folate $(\beta=-2 \cdot 3 ; 95 \% \mathrm{CI}-4 \cdot 0,-0.7 \mathrm{nmol} / \mathrm{l})$ than women with a normal weight. Overweight and obese women also had higher odds for folate deficiency (OR $=1.38 ; 95 \%$ CI $1.03,1.85$ and $\mathrm{OR}=2 \cdot 03 ; 95 \% \mathrm{CI} 1.35,3 \cdot 06$, respectively).

Pre-pregnancy obesity showed a significant association (9\%; $95 \%$ CI 6, 32\%) with increase of ferritin levels compared with women with normal weight. Underweight, overweight and obese women did not have significantly different odds for deficiency compared with normalweight women.

After adjustment for covariates, overweight women had significantly lower serum Fe levels $(\beta=-1 \cdot 7 ; 95 \% \mathrm{CI}-2 \cdot 3$, $-1 \cdot 1 \mu \mathrm{mol} / \mathrm{l})$, and obese women had significantly lower Fe levels ( $\beta=-3 \cdot 6 ; 95 \% \mathrm{CI}-4 \cdot 7,-2 \cdot 6 \mu \mathrm{mol} / \mathrm{l})$, compared with women with normal weight. Women with overweight and obesity had significantly higher odds for serum Fe deficiency $(\mathrm{OR}=1 \cdot 45 ; 95 \% \mathrm{CI} 1 \cdot 02,2 \cdot 07$ and $\mathrm{OR}=3 \cdot 26 ; 95 \%$ CI 2.09, 5.08, respectively).

Compared with normal-weight women, vitamin $\mathrm{B}_{12}$ levels were $6 \%$ lower $(95 \% \mathrm{CI}-9,-3 \%)$ in women with overweight and $15 \%$ lower (95\% CI $-19,-10 \%$ ) in obese 

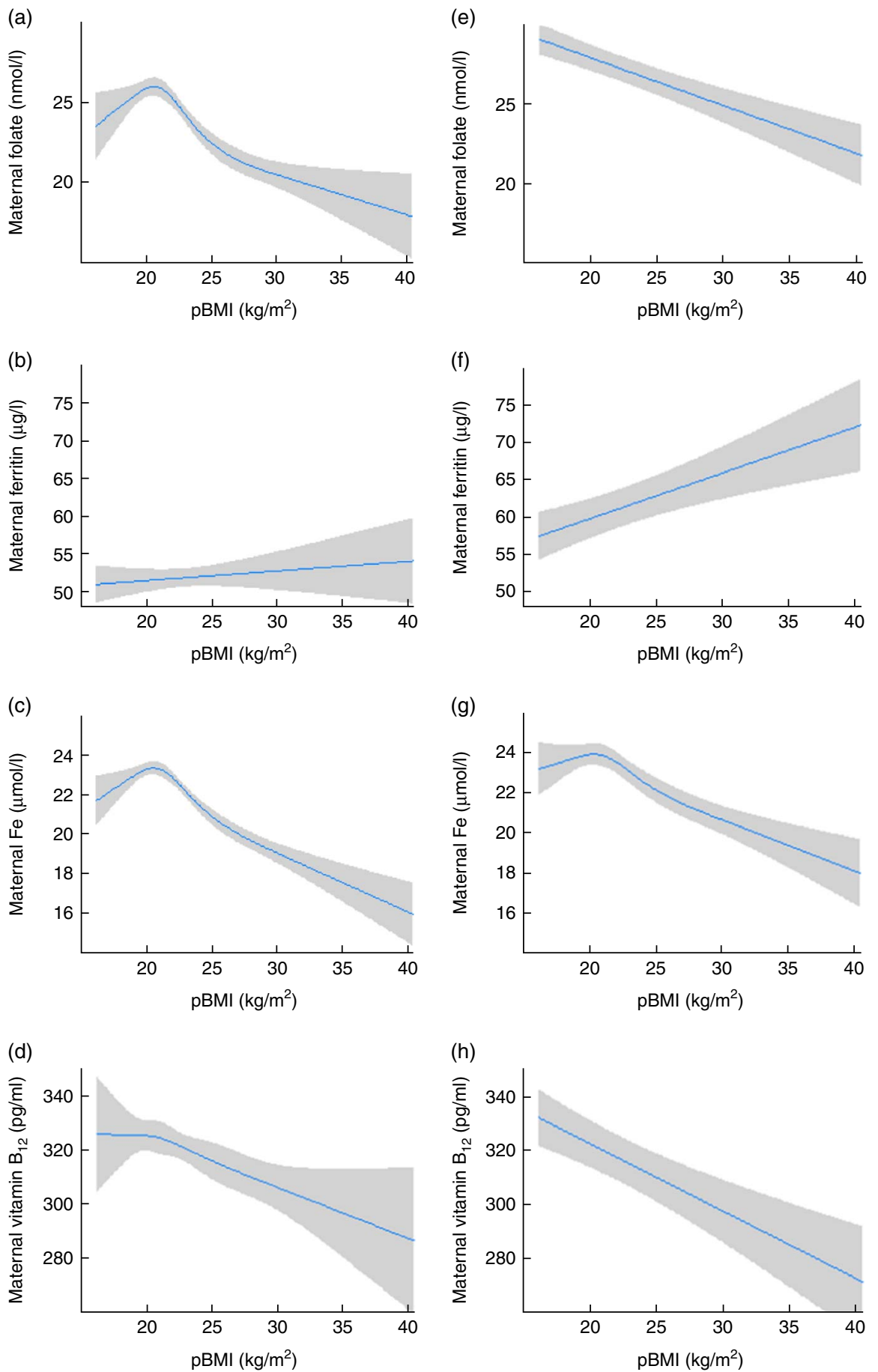

Fig. 2 (colour online) Association between pre-pregnancy BMI (pBMI) and maternal nutrient concentration in early pregnancy among women with singleton pregnancies without diabetes ( $n 4243$ ), the Amsterdam Born Children and their Development (ABCD) study, the Netherlands, 2003-2004. Left panel: association between pBMI and maternal folate (a), ferritin (b), iron (c) and vitamin $\mathrm{B}_{12}(\mathrm{~d})$, standardized for gestational age at blood sampling moment. Right panel: association between pBMI and maternal folate (e), ferritin $(\mathrm{f})$, iron $(\mathrm{g})$ and vitamin $\mathrm{B}_{12}(\mathrm{~h})$, standardized for gestational age at blood sampling moment, and adjusted for maternal age, education, parity, smoking during pregnancy, alcohol use during pregnancy, nausea during pregnancy, weight gain during pregnancy and ethnicity. Restricted cubic spline models, with $95 \% \mathrm{Cl}$ represented by grey shading

women. Overweight and obese women had higher odds for a vitamin $\mathrm{B}_{12}$ deficiency $(\mathrm{OR}=1 \cdot 38 ; 95 \%$ CI $1.08,1.77$ and $\mathrm{OR}=2 \cdot 05 ; 95 \%$ CI 1.41, 2.99, respectively).

The results from the sensitivity analyses on the Dutch population (see online supplementary material, Table S2) and the non-supplement using population (Table S3) showed values similar to those reported in Table 3 . However, in both sensitivity analyses, the association between $\mathrm{PBMI}$ and folate lost significance after adjustment for the covariates. 
Table 2 Mean/median levels and percentage deficiency for folate, ferritin, iron and vitamin $B_{12}$ status in early pregnancy, according to category of pre-pregnancy BMI, among women with singleton pregnancies without diabetes ( $n$ 4243), the Amsterdam Born Children and their Development (ABCD) study, the Netherlands, 2003-2004

\begin{tabular}{|c|c|c|c|c|c|}
\hline Nutrient & All & Underweight & Normal weight & Overweight & Obese \\
\hline \multicolumn{6}{|l|}{ Folate $(\mathrm{nmol} / \mathrm{l})$} \\
\hline$n$ & 3807 & 178 & 2802 & 626 & 201 \\
\hline Mean & $24 \cdot 1$ & $24 \cdot 0$ & $25 \cdot 0$ & 21.7 & $19 \cdot 3$ \\
\hline SD & $11 \cdot 7$ & $12 \cdot 2$ & $11 \cdot 7$ & $11 \cdot 2$ & $10 \cdot 7$ \\
\hline$\%$ deficient & 8.8 & $9 \cdot 3$ & $7 \cdot 0$ & $13 \cdot 1$ & $21 \cdot 8$ \\
\hline \multicolumn{6}{|l|}{ Ferritin $(\mu \mathrm{g} / \mathrm{l})$} \\
\hline$n$ & 4181 & 193 & 3109 & 670 & 209 \\
\hline Median† & 41.7 & 34.8 & $42 \cdot 6$ & $38 \cdot 1$ & $43 \cdot 1$ \\
\hline IQR† & $24.9-67 \cdot 4$ & $23 \cdot 0-60 \cdot 4$ & $25 \cdot 7-68 \cdot 9$ & $23 \cdot 0-61 \cdot 7$ & $23 \cdot 0-76 \cdot 0$ \\
\hline$\%$ deficient & $10 \cdot 6$ & $13 \cdot 0$ & $9 \cdot 6$ & $13 \cdot 0$ & 14.4 \\
\hline \multicolumn{6}{|l|}{$\mathrm{Fe}(\mu \mathrm{mol} / \mathrm{l})$} \\
\hline$n$ & 4003 & 186 & 2980 & 638 & 199 \\
\hline Mean & $22 \cdot 0$ & 21.9 & $22 \cdot 7$ & 19.9 & $17 \cdot 6$ \\
\hline SD & $7 \cdot 3$ & 8.0 & $7 \cdot 2$ & $6 \cdot 7$ & $6 \cdot 9$ \\
\hline$\%$ deficient & $6 \cdot 1$ & $8 \cdot 6$ & 4.6 & $8 \cdot 6$ & $19 \cdot 6$ \\
\hline \multicolumn{6}{|c|}{ Vitamin $B_{12}(\mathrm{pg} / \mathrm{ml})$} \\
\hline$n$ & 4112 & 189 & 3062 & 655 & 206 \\
\hline Median† & $297 \cdot 2$ & $304 \cdot 6$ & $301 \cdot 7$ & $286 \cdot 6$ & $267 \cdot 2$ \\
\hline IQR† & $235.1-377.9$ & $226 \cdot 5-383 \cdot 7$ & $240 \cdot 1-381 \cdot 5$ & $222 \cdot 9-3712$ & $2137-339.9$ \\
\hline$\%$ deficient & $13 \cdot 8$ & $16 \cdot 9$ & $12 \cdot 4$ & $16 \cdot 8$ & $22 \cdot 8$ \\
\hline
\end{tabular}

IQR, interquartile range.

All values are standardized for gestational age at blood sampling moment (90 d).

†Median and IQR are given because of skewed distribution of the variable.

Table 3 Regression models of the association between maternal pre-pregnancy BMI (pBMI) and maternal folate, ferritin, iron and vitamin $\mathrm{B}_{12}$ concentration in early pregnancy among women with singleton pregnancies without diabetes ( $n$ 4243), the Amsterdam Born Children and their Development (ABCD) study, the Netherlands, 2003-2004

\begin{tabular}{|c|c|c|c|c|c|c|c|c|c|}
\hline \multirow[b]{3}{*}{ Nutrient } & \multirow[b]{3}{*}{ pBMI category } & \multicolumn{4}{|c|}{ Maternal nutrient status } & \multicolumn{4}{|c|}{ Odds for deficiency } \\
\hline & & \multicolumn{2}{|c|}{ Model 1} & \multicolumn{2}{|c|}{ Model 2} & \multicolumn{2}{|c|}{ Model 1} & \multicolumn{2}{|c|}{ Model 2} \\
\hline & & $\beta$ & $95 \% \mathrm{Cl}$ & $\beta$ & $95 \% \mathrm{Cl}$ & OR & $95 \% \mathrm{Cl}$ & OR & $95 \% \mathrm{Cl}$ \\
\hline Folate $(\mathrm{nmol} / \mathrm{l})$ & $\begin{array}{l}\text { Underweight } \\
\text { Normal weight } \\
\text { Overweight } \\
\text { Obese }\end{array}$ & $\begin{array}{l}-1 \cdot 0 \\
\text { Reference } \\
-3 \cdot 3^{\star \star \star} \\
-5 \cdot 7^{\star \star \star}\end{array}$ & $\begin{array}{l}-2 \cdot 8,0 \cdot 8 \\
\text { Reference } \\
-4 \cdot 3,-2 \cdot 3 \\
-7 \cdot 4,-4 \cdot 0\end{array}$ & $\begin{array}{l}0 \cdot 8 \\
\text { Reference } \\
-1 \cdot 2^{\star} \\
-2 \cdot 3^{\star *}\end{array}$ & $\begin{array}{l}-0.9,2 \cdot 5 \\
\text { Reference } \\
-2 \cdot 2,-0.2 \\
-4 \cdot 0,-0.7\end{array}$ & $\begin{array}{l}1.33 \\
1.00 \\
1.91^{\star \star \star} \\
3.44^{\star \star *}\end{array}$ & $\begin{array}{l}0.79,2 \cdot 24 \\
\text { Reference } \\
1.45,2.50 \\
2.38,4.98\end{array}$ & $\begin{array}{l}0 \cdot 86 \\
1.00 \\
1.38^{\star} \\
2 \cdot 03^{\star \star}\end{array}$ & $\begin{array}{l}0.49,1.49 \\
\text { Reference } \\
1.03,1.85 \\
1.35,3.06\end{array}$ \\
\hline $\log ($ ferritin $(\mu \mathrm{g} / \mathrm{l})) \dagger$ & $\begin{array}{l}\text { Underweight } \\
\text { Normal weight } \\
\text { Overweight } \\
\text { Obese }\end{array}$ & $\begin{array}{l}-0.10 \\
\text { Reference } \\
-0 \cdot 11^{\star *} \\
-0.00\end{array}$ & $\begin{array}{l}-0.21,0.02 \\
\text { Reference } \\
-0.18,-0.05 \\
-0.11,0.12\end{array}$ & $\begin{array}{c}-0.02 \\
\text { Reference } \\
0.02 \\
0.17^{\star *}\end{array}$ & $\begin{array}{r}-0.13,0.09 \\
\text { Reference } \\
-0.04,0.09 \\
0.06,0.28\end{array}$ & $\begin{array}{l}1.43 \\
1.00 \\
1.38^{\star} \\
1.52\end{array}$ & $\begin{array}{l}0.92,2.21 \\
\text { Reference } \\
1.07,1.78 \\
1.00,2.30\end{array}$ & $\begin{array}{l}1.14 \\
1.00 \\
0.96 \\
0.96\end{array}$ & $\begin{array}{l}0.72,1.80 \\
\text { Reference } \\
0.73,1.27 \\
0.62,1.51\end{array}$ \\
\hline $\mathrm{Fe}(\mu \mathrm{mol} / \mathrm{l})$ & $\begin{array}{l}\text { Underweight } \\
\text { Normal weight } \\
\text { Overweight } \\
\text { Obese }\end{array}$ & $\begin{array}{l}-0 \cdot 8 \\
\text { Reference } \\
-2 \cdot 8^{\star \star \star} \\
-5 \cdot 1^{\star \star \star}\end{array}$ & $\begin{array}{l}-1 \cdot 9,0 \cdot 3 \\
\text { Reference } \\
-3 \cdot 4,-2 \cdot 2 \\
-6 \cdot 1,-4 \cdot 1\end{array}$ & $\begin{array}{l}-0 \cdot 2 \\
\text { Reference } \\
-1 \cdot 7^{\star \star \star} \\
-3 \cdot 6^{\star \star \star}\end{array}$ & $\begin{array}{l}-1 \cdot 0,1 \cdot 1 \\
\text { Reference } \\
-2 \cdot 3,-1 \cdot 1 \\
-4 \cdot 7,-2 \cdot 6\end{array}$ & $\begin{array}{l}2.02^{\star} \\
1.00 \\
1.93^{\star \star \star} \\
5.03^{\star \star \star}\end{array}$ & $\begin{array}{l}1.17,3 \cdot 47 \\
\text { Reference } \\
1.38,2.68 \\
3.38,7.48\end{array}$ & $\begin{array}{l}1.53 \\
1.00 \\
1.45^{\star} \\
3.26^{\star \star \star}\end{array}$ & $\begin{array}{l}0.86,2.71 \\
\text { Reference } \\
1.02,2.07 \\
2.09,5.08\end{array}$ \\
\hline Log(vitamin $\left.B_{12}(p g / m l)\right) \dagger$ & $\begin{array}{l}\text { Underweight } \\
\text { Normal weight } \\
\text { Overweight } \\
\text { Obese }\end{array}$ & $\begin{array}{l}-0.02 \\
\text { Reference } \\
-0.04^{\star \star} \\
-0.12^{\star \star \star}\end{array}$ & $\begin{array}{c}-0.07,0.03 \\
\text { Reference } \\
-0.07,-0.01 \\
-0.17,-0.07\end{array}$ & $\begin{array}{c}0.00 \\
\text { Reference } \\
-0.06^{\star \star \star} \\
-0 \cdot 16^{\star \star *}\end{array}$ & $\begin{array}{c}-0.05,0.05 \\
\text { Reference } \\
-0.09,-0.03 \\
-0.21,-0.11\end{array}$ & $\begin{array}{l}1.42 \\
1.00 \\
1.40^{\star \star} \\
2 \cdot 20^{\star \star \star}\end{array}$ & $\begin{array}{l}0.95,2.12 \\
\text { Reference } \\
1 \cdot 11,1.77 \\
1.56,3.11\end{array}$ & $\begin{array}{l}1.18 \\
1.00 \\
1.38^{\star} \\
2.05^{\star \star \star}\end{array}$ & $\begin{array}{l}0.77,1.79 \\
\text { Reference } \\
1.08,1.77 \\
1.41,2.99\end{array}$ \\
\hline
\end{tabular}

Model 1: standardized for gestational age at blood sampling moment; Model 2: model 1 and additionally adjusted for maternal age, education, parity, smoking during pregnancy, alcohol use during pregnancy, nausea during pregnancy, weight gain during pregnancy and ethnicity.

${ }^{\star} P<0.05,{ }^{* \star} P<0.01,{ }^{\star \star \star} P<0.001$.

†Log transformation was performed because of skewed distribution of the variables.

\section{Discussion}

The present study shows that women with pre-pregnancy overweight and obesity both have significantly lower serum folate, $\mathrm{Fe}$ and vitamin $\mathrm{B}_{12}$ levels during early pregnancy compared with women with normal weight. The prevalence of deficiency among pregnant women with prepregnancy obesity was $21.8 \%$ for folate, $19.6 \%$ for serum Fe and $22.8 \%$ for vitamin $\mathrm{B}_{12}$, while in women with normal weight the corresponding prevalence was 7.0, 4.6 and $12.4 \%$, respectively. This resulted in two to three times higher odds for deficiency of these nutrients in women with obesity compared with normal-weight women. Although women with underweight had lower micronutrient levels and deficiencies were more prevalent than in women with a normal weight, these differences were not significant.

Our results with respect to folate are in line with those of previous studies. A study in a white British pregnant population found that an increase in pBMI was linearly associated with a decrease in serum folate ${ }^{(23)}$. A small study in a US population found lower folate levels in overweight and obese women compared with normal-weight women; 
however, this difference was significantly lower only in overweight women ${ }^{(24)}$. This loss of significance might be due to the relatively small number of obese women ( $n$ 36) included in that study.

In line with our results, a study among pregnant adolescents in the USA found significantly lower levels of serum $\mathrm{Fe}$ in obese women, but no significant association between weight status and ferritin levels ${ }^{(25)}$. A small study in a Spanish pregnant population found lower (but nonsignificant) serum Fe levels in obese women ${ }^{(26)}$.

In the present study, the lower levels of vitamin $B_{12}$ in overweight and obese women is in agreement with two other studies reporting lower vitamin $\mathrm{B}_{12}$ levels in overweight and obese pregnant women ${ }^{(23,29)}$. To our knowledge, however, no studies in developed countries have investigated the association between underweight pBMI and folate, ferritin, Fe and/or vitamin $\mathrm{B}_{12}$ status.

Although both serum Fe and ferritin are markers for Fe status, they showed different associations with weight status. This difference might be explained by the response of ferritin to inflammation in obese individuals ${ }^{(38)}$. Ferritin is a Fe-storing protein, with serum ferritin regarded as a measurement of total body Fe store ${ }^{(39)}$. However, independently from Fe status, serum ferritin is also raised by inflammation in the body, as ferritin is an acute-phase protein ${ }^{(39)}$. Adipose tissue produces cytokines, causing a chronic low-grade inflammation in obese individuals, which may have caused the higher ferritin levels in obese individuals compared with normal-weight women ${ }^{(40)}$. Therefore, ferritin might not be a reliable indicator for $\mathrm{Fe}$ status in obese pregnant individuals.

The underlying mechanism of the relationship between pBMI and micronutrient status is not completely understood. A lower dietary intake of micronutrients before and during pregnancy, as well as biological mechanisms, may play a role. Two studies in US populations found that the diet of obese pregnant women had a lower quality compared with the diet of normal-weight women ${ }^{(41,42)}$. Compared with other pBMI categories, obese pregnant women consumed less whole fruits and more empty calories, such as solid fats, alcohol and added sugars ${ }^{(41)}$. Furthermore, low use of supplements was found in overweight and obese women in our study, and in other studies $^{(41,43)}$. This may be an important determinant of the lower micronutrient status found in this group. However, in our sensitivity analysis in the non-supplement using population, we still found associations similar to those in the total population. This indicates that lower supplement use did not explain the lower micronutrient levels and increased odds of deficiency in women with overweight and obesity.

Besides diet quality, biological mechanisms may explain part of the association between weight status and serum Fe. The Fe-regulating hormone hepcidin is thought to play an important role ${ }^{(38,44,45)}$. Hepcidin expression is enhanced due to chronic inflammation in adipose tissue, a characteristic of obesity, and may be increased in obese women ${ }^{(40)}$. Elevated levels of hepcidin reduce intestinal Fe absorption and macrophage release of $\mathrm{Fe}$, leading to a lower availability of $\mathrm{Fe}^{(40)}$.

Biological mechanisms may also play a role in the association between weight status and serum folate. While obese pregnant women have lower serum folate levels than normal-weight women (in the present study and in others ${ }^{(23,24)}$, higher levels of erythrocyte folate are reported in this group ${ }^{(46)}$. Furthermore, a study among pregnant women showed no difference in absorption of folate between obese and normal-weight women ${ }^{(47)}$. Therefore, it is hypothesized that folate is distributed differently in obese women after uptake, storing more folate in erythrocytes instead of serum ${ }^{(11,46)}$. Especially in the first trimester of pregnancy, nutrients are transferred from maternal serum to the embryo, which might indicate a lower bioavailability of folate for the embryo in obese women ${ }^{(46,48)}$.

Strengths of the present study are the large number of participants and the collection of data on various variables, which allowed us to correct for several potential confounding covariates. Furthermore, the moment of blood sampling took place early in pregnancy, which is the most critical period for the risks of micronutrient deficiencies ${ }^{(6)}$. A limitation was that only half of the participants in the $\mathrm{ABCD}$ study chose to participate in the $\mathrm{ABCD}$ biomarker study, which could affect the generalizability of the present study. The non-response analysis showed that women who participated had a lower BMI, more years of education, used more alcohol during pregnancy and were more likely to be Dutch. Therefore, individuals at higher risk for micronutrient deficiency may be underrepresented in the present study sample, which may have underestimated the effect sizes in the results. Moreover, pBMI was determined by self-reported weight and height of the participants. Participants tend to overestimate their height and underestimate their weight, which could have led to an underestimation of $\mathrm{pBMI}^{(49)}$. However, Shin et al. found that self-reported weight and height was a valid determination of the actual BMI before pregnancy ${ }^{(50)}$. Furthermore, we used non-pregnancy reference values as cut-off values to define micronutrient deficiency. However, due to the metabolic and physiological changes during pregnancy, micronutrient levels might deviate from those in non-pregnant women, possibly making the measurements less reliable ${ }^{(51)}$. Therefore, in the present study, the deficiency prevalences should be interpreted with caution. Currently, due to the absence of guidelines for optimal blood values for folate, Fe and vitamin $B_{12}$ during pregnancy, cut-off values need to be established for the detection of deficiency during pregnancy.

\section{Conclusion}

In conclusion, the present study results suggest that women who are overweight or obese before pregnancy 
have a lower serum folate, $\mathrm{Fe}$ and vitamin $\mathrm{B}_{12}$ status in early pregnancy compared with women with prepregnancy normal weight. Furthermore, our results indicate that women who are obese before pregnancy are more likely to be folate deficient, Fe deficient or vitamin $\mathrm{B}_{12}$ deficient during pregnancy. Further research is needed to confirm these associations and to explore the causality and underlying mechanisms. This is necessary for the development of effective interventions or dietary recommendations for overweight and/or obese women in reproductive age, to prevent nutrient deficiencies before and during pregnancy.

\section{Acknowledgments}

Acknowledgements: The authors thank the participating mothers and their children, and all other persons who contributed to the ABCD study: obstetric care providers, primary schools, students and youth health-care centres in Amsterdam, the Netherlands. Financial support: This work was supported by the Netherlands Organization for Health Research and Development (ZonMw) (grant number TOP 40-00812-98-11010). ZonMW had no role in the design, analysis or writing of this article. Conflict of interest: None. Authorship: J.M.S. and T.G.M.V. developed the concept of the present study as part of the ABCD study. J.M.S. conducted the analyses. All co-authors contributed to interpreting the results and writing the manuscript, and all have read and approved the final version. Ethics of buman subject participation: The ABCD study was approved by the Central Committee on Research Involving Human Subjects in the Netherlands, the Medical Ethical Committees of the participating hospitals, and the Registration Committee of the Municipality of Amsterdam.

\section{Supplementary material}

To view supplementary material for this article, please visit https://doi.org/10.1017/S1368980018000459

\section{References}

1. Zeitlin J, Mohangoo A, Delnord M et al. (2013) The European Perinatal Health Report. The Health and Care of Pregnant Women and Babies in Europe in 2010. Paris: Euro-Peristat with SCPE and EUROCAT.

2. Bartsch E, Medcalf KE, Park AL et al. (2016) Clinical risk factors for pre-eclampsia determined in early pregnancy: systematic review and meta-analysis of large cohort studies. BMJ 353, i1753.

3. Triunfo S \& Lanzone A (2014) Impact of overweight and obesity on obstetric outcomes. J Endocrinol Invest 37. 323-329.

4. Rasmussen SA, Chu SY, Kim SY et al. (2008) Maternal obesity and risk of neural tube defects: a metaanalysis. Am J Obstet Gynecol 198, 611-619.

5. Rahman MM, Abe SK, Kanda M et al. (2015) Maternal body mass index and risk of birth and maternal health outcomes in low- and middle-income countries: a systematic review and meta-analysis. Obes Rev 16, 758-770.

6. Wu G, Imhoff-Kunsch B \& Girard AW (2012) Biological mechanisms for nutritional regulation of maternal health and fetal development. Paediatr Perinat Epidemiol 26, Suppl. 1, 4-26.

7. Kimmons JE, Blanck HM, Tohill BC et al. (2006) Associations between body mass index and the prevalence of low micronutrient levels among US adults. MedGenMed $\mathbf{8}, 59$.

8. Nesby-O'Dell S, Scanlon KS, Cogswell ME et al. (2002) Hypovitaminosis D prevalence and determinants among African American and white women of reproductive age: third National Health and Nutrition Examination Survey, 1988-1994. Am J Clin Nutr 76, 187-192.

9. Tussing-Humphreys LM, Liang H, Nemeth E et al. (2009) Excess adiposity, inflammation, and iron-deficiency in female adolescents. J Am Diet Assoc 109, 297-302.

10. Cheng HL, Bryant C, Cook R et al. (2012) The relationship between obesity and hypoferraemia in adults: a systematic review. Obes Rev 13, 150-161.

11. Tinker SC, Hamner HC, Berry RJ et al. (2012) Does obesity modify the association of supplemental folic acid with folate status among nonpregnant women of childbearing age in the United States? Birth Defects Res A Clin Mol Teratol 94, 749-755.

12. Wronka I, Suliga E \& Pawlinska-Chmara R (2013) Evaluation of lifestyle of underweight, normal weight and overweight young women. Coll Antropol 37, 359-365.

13. Garcia OP, Long KZ \& Rosado JL (2009) Impact of micronutrient deficiencies on obesity. Nutr Rev 67, 559-572.

14. Laraia BA, Bodnar LM \& Siega-Riz AM (2007) Pregravid body mass index is negatively associated with diet quality during pregnancy. Public Health Nutr 10, 920-926.

15. Hermoso M, Vollhardt C, Bergmann K et al. (2011) Critical micronutrients in pregnancy, lactation, and infancy: considerations on vitamin $\mathrm{D}$, folic acid, and iron, and priorities for future research. Ann Nutr Metab 59, 5-9.

16. Berti C, Biesalski HK, Gartner R et al. (2011) Micronutrients in pregnancy: current knowledge and unresolved questions. Clin Nutr 30, 689-701.

17. Krikke GG, Grooten IJ, Vrijkotte T et al. (2016) Vitamin $B_{12}$ and folate status in early pregnancy and cardiometabolic risk factors in the offspring at age 5-6 years: findings from the ABCD multi-ethnic birth cohort. BJOG 123, 384-392.

18. Yajnik CS, Deshpande SS, Jackson AA et al. (2008) Vitamin $\mathrm{B}_{12}$ and folate concentrations during pregnancy and insulin resistance in the offspring: the Pune Maternal Nutrition Study. Diabetologia 51, 29-38.

19. Scholl TO, Hediger ML, Fischer RL et al. (1992) Anemia vs iron deficiency: increased risk of preterm delivery in a prospective study. Am J Clin Nutr 55, 985-988.

20. Lao TT, Tam KF \& Chan LY (2000) Third trimester iron status and pregnancy outcome in non-anaemic women; pregnancy unfavourably affected by maternal iron excess. Hum Reprod 15, 1843-1848.

21. Alwan NA, Cade JE, McArdle HJ et al. (2015) Maternal iron status in early pregnancy and birth outcomes: insights from the Baby's Vascular health and Iron in Pregnancy study. Br J Nutr 113, 1985-1992.

22. Radlowski EC \& Johnson RW (2013) Perinatal iron deficiency and neurocognitive development. Front Hum Neurosci 7, 585.

23. Knight BA, Shields BM, Brook A et al. (2015) Lower circulating $\mathrm{B}_{12}$ is associated with higher obesity and insulin resistance during pregnancy in a non-diabetic white British population. PLOS One 10, e0135268.

24. Tomedi LE, Chang CC, Newby PK et al. (2013) Pre-pregnancy obesity and maternal nutritional biomarker status during pregnancy: a factor analysis. Public Health Nutr 16, 1414-1418. 
25. Cao C, Pressman EK, Cooper EM et al. (2015) Prepregnancy body mass index and gestational weight gain have no negative impact on maternal or neonatal iron status. Reprod Sci 23, 613-622.

26. Garcia-Valdes L, Campoy C, Hayes H et al. (2015) The impact of maternal obesity on iron status, placental transferrin receptor expression and hepcidin expression in human pregnancy. Int J Obes (Lond) 39, 571-578.

27. Jones AD, Zhao G, Jiang YP et al. (2016) Maternal obesity during pregnancy is negatively associated with maternal and neonatal iron status. Eur J Clin Nutr 70, 918-924.

28. van Eijsden M, Vrijkotte TG, Gemke RJ et al. (2011) Cohort profile: the Amsterdam born children and their development (ABCD) study. Int J Epidemiol 40, 1176-1186.

29. Krishnaveni GV, Hill JC, Veena SR et al. (2009) Low plasma vitamin $B_{12}$ in pregnancy is associated with gestational 'diabesity' and later diabetes. Diabetologia 52, 2350-2358.

30. Simcox JA \& McClain DA (2013) Iron and diabetes risk. Cell Metab 17, 329-341.

31. World Health Organization (2016) BMI Classification. http:// www.apps.who.int/bmi/index.jsp?introPage=intro_3.html (accessed December 2016).

32. van Eijsden M, van der Wal MF, Hornstra G et al. (2005) Can whole-blood samples be stored over 24 hours without compromising stability of C-reactive protein, retinol, ferritin, folic acid, and fatty acids in epidemiologic research? Clin Chem 51, 230-232.

33. Goedhart G, van der Wal MF, van Eijsden M et al. (2011) Maternal vitamin B-12 and folate status during pregnancy and excessive infant crying. Early Hum Dev 87, 309-314.

34. Zhang Z, Yuan E, Liu J et al. (2013) Gestational age-specific reference intervals for blood copper, zinc, calcium, magnesium, iron, lead, and cadmium during normal pregnancy. Clin Biochem 46, 777-780.

35. World Health Organization (2015) Serum and red blood cell folate concentrations for assessing folate status in populations. http://www.apps.who.int/iris/bitstream/10665/ 162114/1/WHO_NMH_NHD_EPG_15.01.pdf?ua=1 (accessed October 2017).

36. World Health Organization (2011) Serum ferritin concentrations for the assessment of iron status and iron deficiency in populations. http://www.apps.who.int/iris/ bitstream/10665/85843/1/WHO_NMH_NHD_MNM_11.2_ eng.pdf (accessed October 2017).

37. Academic Medical Center Amsterdam (2016) Laboratoriumbepalingen AMC. Intranet Academic Medical Center. http://www.intranet.amc.nl/web/intranet.htm (accessed October 2016).
38. Nikonorov AA, Skalnaya MG, Tinkov AA et al. (2015) Mutual interaction between iron homeostasis and obesity pathogenesis. J Trace Elem Med Biol 30, 207-214.

39. Kell DB \& Pretorius E (2014) Serum ferritin is an important inflammatory disease marker, as it is mainly a leakage product from damaged cells. Metallomics 6, 748-773.

40. Kroot JJ, Tjalsma H, Fleming RE et al. (2011) Hepcidin in human iron disorders: diagnostic implications. Clin Chem 57, 1650-1669.

41. Shin D, Lee KW \& Song WO (2016) Pre-pregnancy weight status is associated with diet quality and nutritional biomarkers during pregnancy. Nutrients $\mathbf{8}, 162$.

42. Carmichael SL, Yang W, Gilboa S et al. (2016) Elevated body mass index and decreased diet quality among women and risk of birth defects in their offspring. Birth Defects Res A Clin Mol Teratol 106, 164-171.

43. Aronsson CA, Vehik K, Yang J et al. (2013) Use of dietary supplements in pregnant women in relation to sociodemographic factors - a report from The Environmental Determinants of Diabetes in the Young (TEDDY) study. Public Health Nutr 16, 1390-1402.

44. Krause A, Neitz S, Magert HJ et al. (2000) LEAP-1, a novel highly disulfide-bonded human peptide, exhibits antimicrobial activity. FEBS Lett 480, 147-150.

45. Pigeon C, Ilyin G, Courselaud B et al. (2001) A new mouse liver-specific gene, encoding a protein homologous to human antimicrobial peptide hepcidin, is overexpressed during iron overload. J Biol Chem 276, 7811-7819.

46. Shen M, Chaudhry SH, MacFarlane AJ et al. (2016) Serum and red-blood-cell folate demonstrate differential associations with BMI in pregnant women. Public Health Nutr 19, $2572-2579$.

47. da Silva VR, Hausman DB, Kauwell GP et al. (2013) Obesity affects short-term folate pharmacokinetics in women of childbearing age. Int J Obes (Lond) 37, 1608-1610.

48. Sandovici I, Hoelle K, Angiolini E et al. (2012) Placental adaptations to the maternal-fetal environment: implications for fetal growth and developmental programming. Reprod Biomed Online 25, 68-89.

49. Stewart AW, Jackson RT, Ford MA et al. (1987) Underestimation of relative weight by use of self-reported height and weight. Am J Epidemiol 125, 122-126.

50. Shin D, Chung H, Weatherspoon L et al. (2014) Validity of prepregnancy weight status estimated from self-reported height and weight. Matern Child Health J 18, 1667-1674.

51. Wheeler S (2008) Assessment and interpretation of micronutrient status during pregnancy. Proc Nutr Soc 67, 437-450. 